\section{Valentina Vapnarsky \\ Inference crisscross: Disentangling evidence, stance and (inter)subjectivity in Yucatec Maya}

Abstract: This article aims to disentangle values related to evidence, epistemic judgement, and (inter)subjectivity as conflated in two epistemic markers of Yucatec Maya. The particles míin and ma'ak are partial support inferential markers that contrast on the (inter)subjectivity parameter. The analysis, based on a wide and varied corpus approached through token-level usage, provides support for considering (inter)subjectivity as a separate dimension of epistemicity, and proposes that it should be organized among three poles (subjective/intersubjective/ collective-general knowledge).

Keywords: inferential, epistemic, subjectivity, intersubjectivity, stance, Maya, Yucatec

\section{Introduction}

Over the past decade, there has been an increasing number of studies exploring the relation between evidentiality and other epistemic notions, particularly epistemic modality and stance (De Haan 1999; Aikhenvald 2004; Boye 2012; Cornillie 2009, Guentchéva and Landaburu 2007; Hanks 2012, among others). Recent texts on (inter)subjectivity (Nuyts 2001; Narrog 2012) and multiple perspective (Evans 2005; Bergqvist 2015), taken as orthogonal parameters to epistemicity, have introduced new complexities. Analyses such as these have resulted specifically from the fact that values relating to these different notions are often combined in a the first references; see also Tourin actual for (a) polla 2014). However, the precise relation between these values is nasp and tends to be left unspecified, especially in under-deoften not easy to grasp an which benefit from a wide and varied corpus. It is also scribed languages, few of which benefit from a wich which are encoded from those difficult to disentangle those aspects of meaning which although this is a basic that result from different types of pragmatic inference. Alhough or they resolve requisite, cross-linguistic this issue too hastily.
This chapter aims to contribute to this field by disentangling values relating to evidence, epistemic judgement, and (inter)subjectivity as conflated in two epistemic inferential markers of Yucatec Maya, a language spoken by nearly 800,000 people in Mexico. ${ }^{1}$ In keeping with a discourse-centred approach, the categories are apprehended "through token level usage, [by considering] the actual deployment of the forms under interactive circumstances" (Hanks 2012: 169). The two particles - míin and ma'ak - express the epistemic modality of uncertainty or possibility (or "partial support", Boye 2012), as do other Yucatec epistemic markers, in particular wale' "maybe" (Hanks 2007; Vapnarsky 2012, 2013a, in prep). But they differ from the latter because they are also inferentials, conveying that the predication results from a reasoning process based on perceptual evidence or knowledge. They are thus partial support inferentials. Miin and ma'ak contrast in terms of the type of access to, and epistemic judgement of, the referent they index. Broadly speaking, miin is subjective and ma'ak non-subjective, or to use different terminology, they instantiate a direct/non-direct or first-hand/second-hand opposition (De Haan 2001), or to put it in Aikhenvald's (2004) terms, the former would be an "inferred" evidential and the latter more of an "assumed" evidential (Aikhenvald 2004). ${ }^{2}$ However, given the variety of their uses, the precise characterization of their encoded values is less straightforward than it might first appear. Even though míin might seem to encode subjective access to information, in some cases the access is mediated, and miin only conveys a subjective epistemic judgement. However, the hypothesis that views subjective judgement as the primary encoded value is weakened by other facts. As for ma'ak, even though it seems to primarily encode non-subjective access to evidence, one might be tempted to characterize it as an intersubjective form that also marks the speaker's expectation of shared knowledge. However, intersubjectivity might be more a matter of implicature, and

1 The study presented here is part of a more general investigation I have carried out in the last years on uncertainty markers in Yucatec Maya. Parts of the analysis of the inferential uncertainty markers dealt with in this chapter were presented in earlier versions in different meetings: Talking through uncertainty: Linguistic and multimodal analyses of uncertain speech situations, EASA Workshop, University Paris Ouest Nanterre, July 2012; First Intermational Meeting on Yucatec Maya, El Colegio de México, D-F, 4-5 October 2012; ELIA III, Encuentro de Lenguas Indígenas Americanas, Universidad de Rio Negro, Bariloche, May 2013 and FAMLI IV, Form and Analysis in Mayan Linguistics, Universidad del Oriente, Valladolid, November 2016. I thank all the participants of these meetings for their precious questions and comments, in particular Michel de Fornel and Scott Anderbois, as well as the editor of this volume, Zlatka Guentchéva. All misunderstandings are mine. 2 Aikhenvald (2004) proposes the following terminology: "inferred evidential", defined as "information source based on what one can see, or the result of something happening" (Aikhenvald 2004: 393) vs. "assumed evidential", defined as "information source based on conclusions drawn on the basis of on logical conclusion and general knowledge and experience" (ibid: 391). 
the encoded value might strictly reference collective or general knowledge. Mín and ma'ak are thus good examples of the challenge of understanding the semantic and pragmatic intricacies of epistemic and evidential markers.

In section 2, I will start by defining the concepts and corpus of our study. Section 3 offers an overview of the syntactic properties of the inferentials mín and ma'ak. Section 4 will present an analysis of the subjective miin: its use for the estimation of measurements (including a comparison with the other estimative kex), its use for indexing direct-access to evidence, or for indirect access but subjective epistemic judgement, and lastly, its use in questions and play speech. Section 5 will analyse the non-subjective collective ma'ak: its use for inferences based on collective shared knowledge, in the context of situation experienced but involving some type of mediation, its lack of strict encoding of knowledge symmetry, and its relation with perceptual access. In each section, my aim is to provide the reader with a thorough presentation and illustrations of the different

kinds of more or less typical contexts in which each marker is used, in order to clearly show the values they encode and the inference they commonly trigger. This will involve a number of long examples. These illustrations are important because the markers studied here have been described either little or not at all. The examples also show the importance of taking into account local cultural principles of communicative practice and interpretation when elucidating epistemic and evidential values. Section 6 offers conclusive remarks.

\section{Concepts and corpus}

I define evidential as the linguistic marking of the source and type of perceptual or cognitive access to knowledge. Epistemic modality is the expression of the speaker's evaluation of his/her own degree of commitment to the knowledge or belief upon which the statement is based. This includes epistemic judgement, which in the context of inferentials is the speaker's assessment of the degree of validity of the inference (cf. also commitment; or epistemic qualification in Nuyts 2001: 386). I understand subjectivity as applying to both areas: evidentiality and epistemic modality (here instantiated as epistemic judgement). The access may be subjective (personal perception and experience, individual practice, autobiographical memory ...) and the judgement may be subjective ("in my opinion"...), and the two are not always correlated. ${ }^{3}$ Like Nuyts (2001), I assume that subjectivity enters

3 For example, a subjective epistemic judgement may apply to evidence to which the speaker has no subjective access. Obviously there are asymmetries, for instance, cases of non-subjective into a parameter of (INTER)SUBJECTIVITY, but in my view this parameter is made up of (at least) three poles that account for the values potentially encoded by epistemic and evidential markers: subjectivity, intersubjectivity and the collective-general. For the purpose of my analysis, these terms will be restricted to the following definitions:

- Subjective: knowledge sourced/accessed from the field of the speaker's direct experience and/or personal epistemic judgement.

- Intersubjective: knowledge sourced/accessed from the field of the other speech participant(s); it is either shared (you and me) or unshared (you but not me); it reflects the speaker's expectations with regard to the speech participant's epistemic judgement in the here-and-now of the speech event.

Collective-general knowledge: knowledge sourced/accessed from widely shared collective or general knowledge; the speaker is making reference to general opinion (beyond the speech event).

Intersubjective is understood here in a more restricted sense than "intersubjec tive" as employed by Nuyts (2001), who used it to encompass what I designate as collective-general. My view is closer to more discourse-oriented views such as Traugott (1995) or Traugott and Dasher (2002), although I restrict intersubjective here to values inherent to, or prototypically associated with, linguistic forms. In particular, differentiating intersubjective from collective-general knowledge allows us to distinguish among markers expressing that the speaker shares his knowledge with others, those markers which specifically make reference to the addressee's knowledge (they index shared knowledge as construed in earlier discourse and are often used discursively in agreement or disagreement strategies) from those markers signalling that the information or stance is more widely shared as collective-general knowledge (and often shared with the addressee as well, but not necessarily). While the latter can be found designated by the term "general knowledge" in the literature on evidential markers, I add "collective" to the label to refer to the fact that speakers are often aware that their epistemic world is made up of different types of collective knowledge, which is shared to varying degrees, and to which they relate discursively (and in some languages grammatically, as in the Mayan language under study here). In different pragmatic and cognitive theoretical currents (Lyons 1977; Langacker 1990, 2002, Verhagen 2005; Portner 2009), subjective has often been opposed to objective, with diverging views in how the two concepts should be understood (for an overview, see Narrog 2012: 15-24).

judgement applying to subjective evidence, which are rarer (see Heritage 2012; Gipper 2015 and the present chapter, section 3.4 ). 
We take objective to apply to utterances in which the speaker is not indexing any reference to her/his knowledge or anyone else's (thus placing it outside the (INTER)SUBJECTIVE parameter defined here, although we do not rule out the possibility that "objective" could represent a point further away on the subjective $\leftrightarrow$ collective-general $\leftrightarrow$ objective axis). The question of whether such "objective" utterances exist at all in real life, and what type of communicative components should be included in the matter, lies beyond the scope of this paper. In line with Benveniste's pioneering proposals on subjectivity, by using the (inter)subjectivity parameter, our aim is to account for values attached as conventional meaning to specific linguistic forms (Benveniste 1958).

Intersubjective and collective-general can enter into "multiple perspectives" indexation (Evans 2005; Bergqvist 2015) - the property that causes some markers or grammatical constructions "to encode potentially distinct values, on a single semantic dimension, that reflect two or more distinct perspectives" (Evans 2005) - but they involve different types of shared perspective and knowledge dynamics in the interaction. For instance, intersubjective markers are much involved in agreement or disagreement strategies during the speech event, and tend to be interchanged by speakers during conversational interactions (Heritage 2012; Gipper 2015; Stievers et al. 2011), in contrast to collective-general knowledge markers, which may be triggered more by particular discourse genres. Distribution or a/symmetry of knowledge (Hanks 1990; Heritage 2012) is understood in relation to the speech interaction. Therefore, subjectivity always involves some asymmetry of knowledge. By contrast, intersubjectivity involves symmetric knowledge, unless the marker explicitly encodes a differential access or judgement. Collective-general tends to involve knowledge symmetry (the speaker assumes that the addressee and the other participants share the same collective knowledge), although the speaker may be aware that the collective knowledge of the addressee or the other participants is not the same as that which she/he shares with her/his own epistemic group of inclusion. In this sense, it seems relevant to distinguish shared knowledge (shared with others, including or not including the addressee) from symmetric knowledge (shared with the addressee).

I use stance to refer to "the semiotic means by which we indicate our orientation to states of affairs, usually framed in terms of evaluation (e.g. moral obligation and epistemic possibility) or intentionality (e.g. desire and memory, fear and doubt)" (Kockelman 2004). In my view, stance also includes the speaker's evaluation of evidential aspects.

The analysis is based on data recorded in villages of the municipio of Felipe Carrillo Puerto, Quintana Roo, Mexico between 1994 and 2015. In these villages,
Maya is the dominant language in all types of daily interaction (except in school, and recently, in an increasing number of young parent to young children interactions). The corpus used for the study is based on approximately fifty hours of recorded audio and video, as well as transcribed verbal interactions, representative of different conversational and narrative genres. The data was supplemented by examples noted on the spot in day-to-day interactions, as well as by metalinguistic and elicitation sessions on the epistemic markers under study, held in Maya with four native speakers from the village of $\mathrm{x}$ Kopchen ( $x$ K'oopch'e'en in Maya). The aim of these sessions was to gain a more thorough understanding of the linguistic forms and recorded examples. However, with the exception of one small paradigm of examples, all of the illustrative utterances I present in the chapter come from natural interactions. ${ }^{4}$

\section{Syntactic properties of the inferentials miin and ma'ak}

Amerindian languages are famous for grammaticalizing epistemic modality and evidentiality (Aikhenvald 2004; Guentchéva and Landaburu 2007). In these languages, markers of evidentiality usually seem to be inflectional affixes or clitics, contrasting with other languages such as those of Europe, where these notions tend to be expressed by lexical roots or verbal inflexion linked to tense. Yucatec Maya presents what could be seen as an intermediate case, since most epistemic markers are particles that, in this mildly polysynthetic language, have a status midway between grammatical and lexical elements. ${ }^{5}$ They are not affixes, but cannot serve as the base of any affixation or derivation in the way that lexical roots do. They have linear constraints. They are not syntactically obligatory, but pragmatically they often are. The range of epistemic particles of Yucatec Maya present diverse syntactic properties (in particular in relation to linearity and predication). Among this range, however, miin and ma'ak share the same morpho-syntactic

4 At this stage, we do not have access to diachronic data on the inferential markers to complete the analysis and better evaluate some hypotheses presented below concerning semantic and pragmatic changes. In any case, given the limited range of written genres which make diachronic data available in Yucatec Maya, and the discursive nature of the markers analysed, it is most probable that a diachronic analysis would provide a very partial image of their use in earlier times.

5 Aikhenvald (2004: 69) presents a few other Amerindian languages that mark evidentiality with particles (Hopi, Arizona Tewa, and Kamaiurá). 
properties (for míin, examples of most of these properties can be found in Hanks 1984 and Anderbois 2013; the examples given in the next sections of the present chapter complete the illustration for miin and provide them for ma'ak). As shown by the properties below, miin and ma'ak precede the constituent over which they have scope. This implies that with these markers, the speaker first communicates her/his epistemic commitment to the proposition, framing the utterance from the outset as a conjecture or supposition (contrary to other Yucatec Maya par-ticles which are clause final, and hence modalize the information only after its statement, such as the uncertainty marker wale', the mirative bakáan (Anderbois 2016) or the confirmative lo'obal).

a. they precede the predicate (and the focalized constituent, but appear after topic), Yucatec Maya being a predicate-initial language, with the topic usually preceding the predicate, as shown in table 16.1.

Table 16.1: Position of inferential particles miin/ma'ak in the clause structure

(Topic) miin/ma'ak (Focus) Predicate Arguments

b. they apply to independent clauses (except in the case of the estimative use of míin, see 3.1);

c. they cannot function as the main predicate, nor can they be negated;

d. they cannot function as the base of morpho-phonological processes.

\section{The subjective inferential míin}

The epistemic particle miin is used to modalize a statement as a conjecture, as a hypothesis that the speaker cannot fully substantiate. It conveys possibility and inference. But miin also encodes a relation to the subjective field: in most cases the speaker uses miin when the inference is rooted in direct, perceptual evidence from the situation. We will show that miin can also be used in situations of indirect evidence, in this case, it conveys a subjective stance about what is inferred, similarly to "in my opinion" or "in my view". The subjectivity entailed by míin is also revealed by the translations provided by Yucatec bilingual dictionaries: Bricker et al. (1998: 185) give "I suppose", and the Maya Popular dictionary (2003: 164) proposes "creo que, quizá, a lo mejor" ("I think that, maybe, perhaps"). In addition to these brief mentions, miin is analysed as conjectural in Hanks 1984 and Anderbois 2013 (see 4.6).

\subsection{Estimation of measurements}

A very common function of míin is to indicate the estimative nature of a measurement, which can be of any type, such as size in examples (1) and (2), quantity in (3) and (5), or temporal location in (4). This function represents about a third of the examples of our corpus. The measure is generally expressed as a nominal clause or an adverbial complement. In (1), a woman explains that when she was hunting for an agouti, a big stone fell on her as she tried to enter a cave. To estimate the size of the stone in her story, she compares it to the hearthstone she is looking at while speaking. This perceptual act of approximate comparative measurement is expressed by miin.

(1) 1. Noxi woolis tunich nojoch buka'aj! Mîin buk le k'ooben-o'. Big round stone big MEASURE INF.S MEASURE DET hearth-TD A big round stone, as big as this! About the size of the hearth stone.

2. Buka’aj le tunich lúub tinwóo'lo'!

The stone that fell on me was this big!

[xisa-vva0154-1996]

In (2), the speaker estimates how old he was when he lived through the period of poverty that followed the war. His words míin buka'ajena' "maybe about this size" are accompanied by a gesture pointing at a child of an equivalent age.

(2) 1. Teene' 'oora'ako' inwilmaj pero teene' ma' nojochen 'oora'ako' $\mathrm{Me}$, at that time, I saw it (= experienced it), but I wasn't big at that time,

2. müin buka'aj-en-a'!

INF.S MEASURE-B1-TD,

I was about that size!

In (3), an old man remembers the farm where he lived as a child, and the many domestic animals they had; he estimates their number by recalling personal memories of his life.

(3) 1. Pos tene', ka jlúuk'en ten Xek Pich, tu'ux kajakbalo'ono', Well, when I left Xek Pich, where we used to live,

2. yaan- $\varnothing$ ten miin kwareentajun-túul u-kaax, EXIST-B3 PR1 INF.S fourty one-NC A3-chicken I had about forty chickens, 
3. kaax-óo' bey tak e x-nuk kaax-o' je'el-a', chicken-3PL MOD until DET FEM-old chicken-3PL OST-TD, chickens, the hens were as big as this,

4. yaan-Ø to’on miin kex dyes wa kïnse jun-túul u-k'éek'en,.... EXIST-B3 PR2PL INF.S CONC ten or fifteen one-NC A3-pig we had about ten or fifteen pigs...

[mak-vva0091-1996]

In (4), the speaker is describing the onset of a cyclone that he experienced years ago. He remembers that it started around the same time of day as when he was talking.

(4) 1. pero le ka a'la' mïn walaaji-ak but DET CONJ say INF.S TP.ADV-PAST

tuka'aten-o' ... But when it was about this time of day again,

2. tuka'aten u-líik'-i muunyal-óo' again A3-rise-vL cloud-3PI

again the clouds rose [mak-vva0085-1997]

Finally, in (5), the speaker estimates the size of the field in which he is currently planting beans.

(5) 1. ten ba'ax kinpak'ik be'ooráa' estee bu'ul, Me, what I'm planting now it's ... beans,

2. miin t-in-pak'-ik míin seys mekates bu'ul, tsama'-bu'ul, INF.S PROG-A1-plant-IPF.TR INF.S six mecate bean tsama'-bean let's say I'm planting about six mecates of beans, tsama' beans

All these examples are very representative of miin uses. In all instances, the estimation involves direct personal access to the referent, which is evaluated through perception, practice and/or personal memory.

\subsection{The subjective estimative (miin) vs. the neutral estimative (kex)}

When the estimation is not based on direct subjective access to the referent, another particle, kex, is favoured. Kex is a concessive marker that serves to introduce "even if" clauses, as in (6).
(6) kex táant u-síij-l-e' bey-a, túun-chu'uch-(i)k u-chan k'a' CONC RETROS.IM A3 -born-VL-TD ${ }_{4}$ MOD-TD, PROG.A3-sucke-IPF.TR A3-small hand Even though she's just born, she's (already) sucking her little hand

But kex also signals approximation when estimating measurements. The facts presented below confirm that míin indexes subjectivity of access in the estimation of measurements, and also that contrary to míin, in its estimative function kex is neutral in terms of the type of evidential access.

It is not unusual for kex to co-occur with miin, as in (3) above, line 4. However, kex is used on its own, without miin, when the estimation is based on indirect access to the referent. This is typically the case in traditional narratives. A survey of the distribution of kex vs. miin in this genre shows that kex is considerably more frequent, and that the few instances of miin are framed as quoted speech, in which míin indexes the perspective of the quoted character. ${ }^{6}$ For this analysis, it is important to clarify that Yucatec Maya has both a generic hearsay marker (bin, hearsay most often from an indefinite source, translated in the examples as "they say") and a quotative marker ( $k$-ABS). Only the latter presents the reported statement as a verbatim quotation and maintains the indexical frame of the reported speech event (see also Lucy 1993). All three examples below come from the same story about the origin of the sacred crosses in the region. The story takes place during the "war", in the early days of what is regarded as present-day humanity, a time the speaker has heard much about but did not see. ${ }^{7}$ In (7), the estimation, which concerns the size of the tree on which the very first of these crosses is said to have been found, is explicitly presented as part of reported speech, signalled by the hearsay clitic bin.

(7) 1. Sile che'-o' yaan- $\varnothing$ kex bin de seeys meetros Si DET tree-TD 2 EXIST-B3 CONC REP CONJ six meters but this tree, it's about, they say, six meters ...

2. wa de syeete meetros ka'anl-i(l)! DISJ CONJ seven meters high-NOM or seven meters high! [mak-vva0098-1996]

6 There are a very few exceptions to this. One possible way to explain them is to consider that they occur when the narrator adopts the perceptive of a protagonist, as an instance of discursive polyphony. We leave this topic for further investigation.

7 The "war" the Mayas refer to is the indigenous rebellion historically known as the Caste War, which took place on the Yucatan Peninsula, 1847-1901 according to Mexican history, although the Mayas consider that it lasted much longer. 
In (8), the sizes of some parts of the tree are now described, a branch fork and a little hole in the trunk. Note that for the latter, the speaker adds a gesture to his descrip-tion to show the approximate size of the hole. Despite this gesture - reinforced by the terminal deictic $a$, which signals immediacy of access, and typically accompanies ostensive gestures - no mïn is used, only kex. This choice reveals that in selecting an estimative marker, indirect access to the primary referent (the speaker never saw the tree) predominates over the speech event context. This indirectness/non-subjective-ness is also overtly signalled by the recurrent use of the reportative bin.

(8) 1. koomo le seedro

as DET cedar

as the cedar,

2. yaan-Ø kex buk u-nak' uy-óox toop'-i le seedro EXISB3 CONC MEASURE A3-belly A3-three bud-NOM DET cedar tun bin- $a$, thus REP- TD

it was about that size, the three-forked branch of the cedar tree, they say

3. te' tun bin uchan kweeba yan kex buk ujoboni bina', there, in its little cave, the hole was about that size they say

[mak-vva0098-1996]

By contrast, (9) illustrates one of the very few instances of miin (co-occurring with kex) in the same narrative. Míin occurs here in the context of direct quoted speech, signalled by the verbatim quotative $k$ - The narrator speaks as the "animator" (below, "animator" and "author" are used in Goffman's sense) of the main character's words: with miin, the main character - or "author" - estimates the time the candle must have been burning on the tree, given the large drops of wax that cover the trunk. Miin is allowed and expected here because now, given the quoted-speech framing, it is the narrated event (and the author's perspective) rather than the speech event (and the animator perspective) that determinates the indexical marking, and this triggers a subjective estimation.

(9) 1. Le ba'ala' ma' táantike’ senyoora! Ki' bin. This thing, it's not new madam! He said they say.

2. Le ba'al-a' míin yaan-Ø kex sïnko wa seeysaanyos DET thing-TD, INF.S EXIST-B3 CONC five DISJ six years this thing, I suppose it must have been burning for about five or six years

3. ts'óok uyeele' le saanto kib te'la', ki' bin. The candle there, he said they say.

[mak-vva0098-1996]
The distribution of kex (with no miin) vs. miin (in quoted speech) in narrative genres confirms that mîn conveys subjective access (and most often direct perceptual access) when used in measurement contexts. The next section will show that mín also indexes subjectivity in non-measurement-estimation uses, but that in these other cases, subjectivity of epistemic judgement can surpass subjectivity of access.

\subsection{Other inferential uses based on direct access to evidence}

In non-measurement uses, miin most often occurs in situations where, similarly to the measurement-estimation use, the inference is based on premises connected with the perceptual field of the speaker, or direct cognitive knowledge, such as in (10) and (11) below. Mín also helps signal that the statement is a personal supposition. This subjective stance is very often reinforced by the combination of miin with the idiomatic subjective attenuators (in)wake (< kinwa'alike" "I say it") "according to me" "to my opinion", as in (10) to (13), or bey inwoojle" "to my knowledge".

In (10) a man (S1) visits a ritual specialist, $j$ meen, (S2) for a purification sweeping. Shortly after he arrives, he explains his pains by pointing at different parts of his body, and then suggests a hypothetical cause. His aetiological guess (a bad wind) comes from the feelings in his body, as well as from his personal knowledge of occasions when the wind might have caught him. And this is just a supposition. All of this is conveyed by the use of miin.

(10) 1. S1: (...) Ma' chen junp'e diya ka tyala tunk'íinam te'ela', tunk'íinam, And is it not that one day, it was hurting here, it was hurting,

2. kaj liik' te'la', ka p'u bin te'la' and it went up here, and then it started to go here (shows how the pain rose from his arm to his shoulder and neck),

3. myeentras tak inkaal ubin, chachmil umenmile'; and at that time, it was even going to my neck, it grabbed me

4. Junp'el ink'ab je'la', maadre lelo' jach utopmaj! Chïngas uk'íinama tun! This one hand, my gosh it really ruined it! Damn, what pain!

5. S2: bey, jach jaaj xíib That's how it is, that's very true man

5. S1: Puuta k-inw-a'a-(i)k le ba'al-a' míin iik'- $\emptyset$ damn ICP-A1-say-TR.IPF DET thing-TD, INF.S wind-B3 $k$-inw-a'a-(i)k-e'. ICP-A1-Say-TR.IPF-TD 


\section{Damn, I say, this, this may be wind, I say.}

6. S2: (to other visitors) P'aat injan atender le 'aamigoe'. (to S1): Máaneni'. Wait, I'm quickly attending to the friend. (to S1): Come in.

[tor-D3-GA-P2-2007]

The following example (11) is taken from the same conversation as (3) above. The man had moved to a new home, where his poultry and pigs had quickly begun deteriorating and dying. Before going to see the ritual specialist, the man had had a conversation with his brother, which he re-enacts in his long story. In this extract, he is suggesting to his brother that the field is cursed. The personal, autobiographical experience on which the events are based and the subjective nature of the supposition are reflected in, and asserted with, the use of miin. The discourse is framed as quoted speech by the quotative $k$ in first person (ken) at the end, line 3.

(11) 1. - 'Pos le ba'ala' 'ermaano', de por sile', 'Well, this, my brother, in fact,

2. inw-a'-k-e' míin waay-bi meent-ab- $\emptyset$ le teereno' A1-Say-TR.IPF-TD ${ }_{4}$ INF.S curse-PART do-PAS.CP-B3 DET field tu'ux yaan-ak-en,

where EXIST-INTR.SBJ-B1

I'd say that the field where I was might have been cursed,

3. yóosa munyaanta to'on mix junp'e klaase 'áalak' waye', ken ti'. so that we couldn't have any sort of domestic animal there, I said to him.

[mak-vva0091-1996]

\subsection{Míin use with non-direct evidence, but subjective epistemic judgement}

Rarer, but nevertheless possible, are uses where the conjecture presented by míin is not based on direct subjective evidence. This is found especially in comments about old non-biographical times, or prophesied times-to-come such as in (12) and (13), or in speculations about matters to which one has no experiential access, such as in (14). As we will see in the section 5, in these contexts, the expected inferential marker is ma'ak. But the use of miin in such cases signals that, despite indirect access to the referent, the conjecture is a personal opinion of the speaker. Thus here, mín does not index subjective access to the evidence, but rather a subjective judgement on the facts.
(12) was uttered after the speaker had narrated the story of a fantastic animal, said to have killed and eaten people a few generations ago. In this extract, the speaker supposes that what was known as the boob might in fact be the "lion", which he has heard about and once saw in a picture (this was recorded before the introduction of electricity and television in the village). All the speaker's references to the boob are indirect (hearsay and mediated visual access).

(12) 1. as.kweenta boob tumen (.) pero míin lete leon inw-ay-ik CONJ boob because but INF.S PI3 DET lion A1-say-IPF.TR we can think it's the boob because... but I suppose this is the lion I'd say

2. faasil beyo' tumen úuchben nukuch máakob-o' it's probably that because the ancestors

3. boob ya'ako' jaaa bey uts'a'amilob uk'aabao' they said Boob, haa, that's the name they gave to it.

[pascbob-1994]

In (13), an old woman talks about the different doomsday prophesies, a topic often discussed in the region. Her knowledge of the prophecies is hearsay; but here she suggests the doomsday that she personally thinks would be the least painful.

(13)
pero t-inw-a'a-(i)k
uts geera ka
but PROG-A1-Say-IPF.TR CONJ INF.S more good war liik'-ik- $\varnothing$

raise-SBJ.INTR-3B

but I say that it would probably be better if war arises

\section{2. ke yete le eele ka meeto'}

than that fire occurs

[xisa-vva0153-1995]

Finally, in (14), another woman is answering a question I had asked about the location of the sun, during an interview about cosmology. She can see the sun of course. But this does not provide her with the clues necessary for understanding precisely where the sun is located in the different sky layers that make up the Maya cosmos. With miin, she hypothesises that even those who travel in planes cannot know. This thought has just occurred to her, and she has never expressed it before. It is based on indirect knowledge but she experiences and conveys it as a very personal opinion on that topic.

(14) 1. V: tu'ux yan le k'iino'?

Where is the sun? 
2. J: lelo' ken sa' tu'ux?! tu'ux t at'aan le je'elo'? That who knows where?! Where is it according to you?

3. lelo’ mix máak ojeelmil inwa'ik. Lelo’ mix máak ojeelmi! That, nobody knows I'd say. That, nobody knows!

4. Mín mix le k-u-bin-o' ka'an-o' muny-il-ik-óo', INF.S NEG.EMPH DET ICP-A3-go-3PL sky-TD 2 NEG.PROG.A3-See-IPF.TR-3PL I suppose not even those who travel to the sky, they don't see it

5. munk'uchlo'bi', ay wa k'uchke' yeelo'be'! they don't get there, uy if they got there, they would burn!

These examples show that even if direct access to the evidence is an important feature of míin, it is not a necessary value (see also sections 4.1.1 and 4.1.2).

The subjectivity encoded by mín is further confirmed by the fact that mín is most often combined with first-person predicates, as in (10) and (11). Naturally, the third person appears more often in the indirect access cases presented in this section. As for second-person subject predicates involving mín, these mostly concern polar questions, to which we now turn.

\subsection{Questions and play speech}

\subsubsection{Polar questions (about facts concerning the addressee)}

As a corollary of the cases analysed above, mín is also frequently used in questions that offer a personal supposition calling for a confirmation from the addressee. In the situation, the supposition is generally based on some immediate aspect that is perceived by the speaker, but concerns the addressee. In (15), after I step on a dog's tail and shout in surprise and fear, the worried owner of the house promptly approaches me and asks if her dog has bitten me. She did not see the incident but heard my shout (sensory-auditory access), and is guessing what happened.

(15) 1. V: $\begin{aligned} & -A y ! \\ & -O w !\end{aligned}$

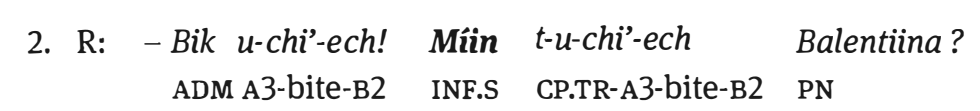

- Careful it doesn't bite you! Might it have bitten you Valentina (as it seems to me)?
In (16), a woman reports her conversation with a woman who has come to attend the village festival with her daughter. The conversation is rendered in quoted speech, framed by the verbatim quotative $k$. When she saw the woman waiting for a van, she asked her if she was planning to take her daughter back to their village. Again, the supposition is based on some perceptual-visual evidence (the visitor waiting for the van) and presented as a personal guess.

(16) 1. tinw-a'al $t$ e nojoch máako', PROG.A1-say PREP DET big person-TD 2 I said to the lady,

2. mïn yan a-bi-s-(i)k a-'iija-o' ken ti, INF.S OBL A2-go-CAUS-IPF.TR A2-daughter-TD, QUOT.B1 PR3 maybe you're taking your daughter away (as it seems to me)? I say to her.

Notice that in both (15) and (16), miin modalises a predicate concerning an addressee's circumstances to which the speaker has some perceptual access, though less than the addressee her/himself. These examples could therefore be considered cases of (relative) symmetric knowledge (the speaker shows that s/ he is aware of some circumstances concerning the addressee). However, basic Mayan principles of communicative interaction rather tend to favour the interpretation that the speaker uses the subjective míin to avoid making an assumption about the viewpoint and experience of the addressee/other without previous confirmation. This is part of a more general cultural and linguistic stance to avoid asserting something that one is not entirely sure of and has no direct access to. Consequently, here míin also indexes an asymmetric relation to evidence.

\subsubsection{Play speech}

Finally, miin is characteristic of the genre báaxal-t'aan (play speech), in its gentle form. ${ }^{8}$ In this dialogic genre, speakers make clearly false statements to their addressee. The humorous statement connects a detail of the situational context to a fact about the addressee, one that the speaker might want to indirectly criticise, compliment, or just make fun of. In (17), one woman teases another who arrives very late for group work during the village festival.

8 Other languages have been reported to use inferred inferentials for irony and sarcasm (see Aikhenvald 2004: 322). 
(17) Muin jóok'-ech cha'an 'óonyak!

INF.S go.out-B2 watch last.night

Maybe you were out watching [the festival] last night?! [maakan-2007]

(18) was said to me during the first minutes of a visit with some friends. When I arrive without my son, the man makes fun of me, referring to the fact that I often left my young son in the care of other women in the village. Notice that both jokes are based on perceptual evidence, as is common in the genre and correlates with the subjectivity of miin.

(18) Tu'ux yaan- $\varnothing$ e Mateo $x$ Balen? Míin t-a-si-aj? Where EXIST-B3 DET PN FEM PN INF.S CP.TR-offer-TR.PF Where is Mateo Balen? Or maybe you gave him away? [rosi8:17.40-2008]

Besides being triggered by the direct-access evidence condition, míin in báaxal-t'aan forms seems to help attenuate the provocation by marking the idea implied by the question as only assumed by the speaker (and potentially not shared by others).

\subsection{Summary and discussion of miin}

The analysis of the different uses of miin shows that this particle is often linked to the expression of subjective perceptual access to information, indicating an asymmetry of knowledge distribution among the speech participants. This is typically the case in the measurement-estimation function of míin, which represents a large proportion of its uses. It is also predominant in non-measurement cases, but among these it is possible to find contexts in which mín is used in situations of indirect non-subjective access to evidence, in order to signal more that the inference is a personal judgement.

One question is whether or not the marker should be analysed as basically a marker of subjectivity of epistemic judgement (a value that always appears to be present when míin is used) on which the value of direct access, or asymmetric knowledge, would be dependent. At first sight, this analysis would seem more economical, and could explain the fact that (i) míin is used even in cases of indirect access if there is subjectivity of epistemic judgement and that (ii) we have found no clear case of direct access and non-subjective (or intersubjective) judgement expressed by míin. Recent analyses of epistemic markers have offered similar interpretations, in which access to evidence or the indexation of knowledge distribution is seen as dependent on (inter)subjective epistemic judgement (e.g. Gipper 2015: 216). However, as Gipper (2015) mentions in her study of the Amazonian language Yurakare and two of its epistemic forms that seem semantically very similar to míin/ma'ak, subjective judgement is rather neutral in terms of expectations regarding access to knowledge. In fact, for the Yurakaré subjective marker that Gipper analyses (-laba), subjective stance occurs just as frequently in cases of both symmetric and asymmetric (access to) knowledge. This contrasts with Yucatec uses of míin. In my view, the fact that míin occurs predominantly with direct access and asymmetric knowledge (including when it functions as a measurement-estimative) argues in favour of considering these values an essential part of its meaning. Furthermore, míin is not commonly used in responses marking the kind of disagreement or misalignment that would be expected with a marker primarily expressing epistemic judgement. Consequently, I would hypothesize that subjective access is the primary (diachronic) encoded meaning of miin, the subjective epistemic judgement being pragmatically conveyed. Through the conventionalization of pragmatic implicatures, the subjective stance becomes tightly attached to the form, to the point that in some uses, a shift occurs from subjective access to subjective epistemic judgement. ${ }^{9}$ This explains why mín can be used in cases of indirect access to evidence or more symmetric knowledge, though these are less common. Moreover, the fact that sentences with míin are very often modalized by additional subjective attenuators like "in my opinion" or "according to me" confirms that muin tends to occur with an overall subjective stance, but it also reveals that the speakers need these expressions to explicitly express a personal judgement that is, or was, only inferable when using míin.

Anderbois (2013) analyses míin as a conjectural evidential, following Hanks (1984) and Faller (2002)'s subcategorization of inferentials. Anderbois argues that mín can be used for the two sub-types of inference that, according to Faller, characterize "conjectural": (i) inference with direct evidence and (ii) "reasoning" based on general knowledge and personal experience. We have shown several contexts in which miin can be used with direct evidence. This is its typical subjective frame of reference. As for "reasoning" as defined above, according to our data, míin can only be used (a) if the reasoning is also grounded in aspects of the predication to which the speaker has direct perceptual, practical or memory access or, (b) in cases where there is no such direct access, if the speaker wishes to express the subjectivity of her/his epistemic judgement. We will now see that in

9 Our conclusion contrasts with Anderbois (2013 submitted)'s analysis which considers that mín is primarily an epistemic modal and that the restriction to indirect evidence is an epiphenomenon of the semantics of uncertainty (Anderbois 2013: 9). 
Yucatec Maya, a different marker is used when the inference is based exclusively or primarily on general knowledge.

\section{Ma'ak: Inference and uncertainty in the field of collective knowledge}

The particle miin contrasts paradigmatically with a second inferential epistemic marker: ma'ak. The particle ma'ak shares the same syntactic properties as míin, and the two never co-occur. Furthermore, ma'ak also expresses inference and conveys the same epistemic form of possibility or partial support as mín: the statement is presented as inferentially obtained (through presumption, deduction or abduction) and subject to a degree of scepticism. But in contrast to miin, ma'ak signals that the statement is a supposition whose clues are not centred on the speaker's subjective field, are not the immediate evidence of perception or personal memory, but are rather indirect and mediated. However, the distribution of the domain of ma'ak does not neatly complement that which is covered by miin. Whereas míin rather widely indexes directness of access and subjectivity, ma'ak is more specifically used for non-subjective evidence falling into the category of collective-general knowledge, based mostly on hearsay (but distinct from the hearsay markers). ${ }^{10}$ This also means that it is not intersubjective in the strict sense of the definition in the introduction. Intersubjectivity (the expectation of symmetric knowledge) is nevertheless often conveyed by implicature.

The combination of ma'ak values of inference and non-subjectivity of access can lead to two apparently opposite epistemic interpretations, depending on the context: it can be considered (i) dubious, because the evidence does not come from the personal field, or (ii) probable, because it is linked to (widely) shared knowledge and presumably, for the speaker, a shared stance.

The particle ma'ak, often contracted to mak, is not reported in published dictionaries of contemporary Maya, most probably due to dialectal variation. My own data suggests that it is rarely or never used in Campeche and Yucatán, where most of the lexicographic work has been done. ${ }^{11}$ However, it is frequently used in the eastern dialects spoken around Valladolid and Felipe Carrillo Puerto.

10 Hearsay is expressed by other particles: the reportative bin and the quotative $k$-, previously illustrated with miin and appearing in an example with ma('a)k in (21) below; see also Lucy 1993. 11 Also pers. com. by Briceida Cuevas Cob for Campeche and Fidencio Briceño Chel for Yucatán.
An arguably related form, ma'k or ma'ki' (Diccionario de Motul), (ix) ma'kil (Vocabulario de Viena) "por ventura no, quizá no" ("by chance no, maybe not"), is reported in the earliest colonial dictionaries of the 16th and 17th centuries (Barrera-Vásquez 1981: 480, 482). The form of the dictionaries' quotations and their proposed translations could indicate that the particle is etymologically related to the negative marker $m a \cdot{ }^{12}$ In any case, these early reports suggest that the dialectal variation observed nowadays results from the decreasing use in some regions of a particle that was once more common.

\subsection{Ma'ak for inferences based on shared collective knowledge}

Given the meaning of ma'ak, it is not surprising that it is most frequently used in talk about old times, prophesied future times, folktales and matters to which the average person has only indirect and mediated access, such as the details and intricacies of the non-visible supernatural world. The following examples illustrate these contexts.

The first example, (19), is taken from a long conversation between two men, Don Juan (J) and Don Eu (E) (see Vapnarsky 1999, vol. II text 6). In this extract, the men are talking about former times and how people used to live. Don Juan, the oldest man in the village, is very confident about facts (which is typical of him, but is reinforced by my presence and the recording situation), whereas Don $\mathrm{Eu}$, in his forties, adopts a much less affirmative stance, inquiring and supposing rather than asserting. This is seen clearly in the following extract, in which Don Eu introduces the topic of the clothes worn by the elders. At that moment, Don Juan had just talked about his father, and Don Eu is making reference to that generation of people, whom he did not know, or only knew when he was very young, and does not remember clearly.

(19) 1. J: (...), pos inpapa leti' koomo ya'abubeetik koole', pos ma't seen'ilaj o'tsilili'. My dad, as he worked a lot of fields, we didn't experience much poverty.

2. E: Mak le úuchij, mak bey tak le nook'-o' mak mina'an-Ø? INF.C DET long.ago INF.C MOD even DET cloth-TD ${ }_{2}$ INF.C NEG.EXIST-B3

12 Pérez (1866-77) suggests another possible etymology maaki "puede ser que no, parece sub juntivo de maakhal [no ser, no llegar a ser o tener resultado]" ("maybe not, it seems a subjunctive form of maakhal [not to be, to not manage to be or have results]") (Barrera-Vásquez 1981: 483). Pio Perez seems to have based his mention of maakion the use of the particle as found in the Arte of Beltran de Santa Rosa (Beltran de Santa Rosa 1859 [1746]). 
Maybe in old times, maybe clothes like those, maybe thereweren't any (as we can suppose from what we know)?

3. J: Ba'ax nook'e' tun kunyaanta tech! Ba'ax 'óosa tun kak'uuch? What clothes could one have had! And what did one spin for, then?

4. E: Chen bey uweenelo'bo', chen j wi'it'!

They slept just like this, they were just people with loincloths!

[jua-eul-vva0028-1995]

The use of ma'ak in line 2 by Don Eu signals that the statement "there were no clothes (like today's)" is a supposition based not on personal experience, nor on anything the speaker has previously heard about in these precise terms, but rather on his general knowledge of those times, about which he has good reason to think his interlocutor knows more. In Don Eu's words, the intonation and the use of ma'akalso have a questioning effect. They call for a confirmation from Don Juan, his elder addressee. Don Juan's answer emphatically confirms Don Eu's supposition. And Don Eu's subsequent comments in line 4 show that he is falling into line with the elder's words.

In example (20), a man comments on the success of a ritual for rain, and on the powerful action of the guardian spirits that are invoked during this type of ceremony. Not being a ritual specialist himself, he has no legitimate reason to assert any direct personal knowledge on the matter. In Mayan terms, what he knows or can infer has to be presented as second-hand information. Furthermore, the inference expressed by ma'ak is itself part of a statement expressing a commonly shared conjecture.

(20) 1. (...) máan le 'áaka’bo', graasya tunmeyaj, the night passed, and the offerings were working

2. beendisyon jajal dyoos, ubendisyoon le nukuch máak, this was the blessing of True God, the blessing of the guardian-spirits,

3. ma'ak e nukuch.máak-o'ob-o'

INF.I DET big.PL.man-3PL-TD probably the guardian-spirits,

4. leti'-o'o' manejar-t-ik tulaaka le meyaj bey-a'. PR3-3PL govern-TRZER-TR.IPF all DET work MOD-TD they govern this type of work [mak-vid1:29:52-30:02-2005]

The next example (21) shows a similar type of inference, but it does this by combining different epistemic-evidential markers. After relating a well-known episode from a mythical story about how in ancient times, people used to carry their firewood just by whistling, the speaker speculates on how this might have worked. He suggests that the whistle probably had special powers.

(21) 1. (...) tujun kutaal! Teeche’ táanxúu'xu'! It came on its own! You, you were whistling!

2. Mak espesyal- $\varnothing$ u-xúu'xu' bin wal-e'. INF.C special-B3 A3-whistle RS POSS-TD Their whistling may have been special maybe they say.

3. Bey u'istoorya bey utsikbatik 'aanima inmaadrinai.

That's the story as my godmother used to tell me. [mak-vid145:20-2005]

Notice that the statement is framed by three evidential-epistemic particles: ma'ak, the reportative bin and the epistemic wale' conveying possibility (Hanks 2007; Vapnarsky 2012). Ma'ak introduces the hypothetical statement as an inference that is based on collective knowledge. The use of the reportative bin (hearsay without a definite source) in the same predicate makes it explicit that the supposition (and not only the evidence) is shared by hearsay. Therefore, the final comment of the speaker in line 3 ("That's the story as my godmother used to tell me") is easily understood as referring not only to the narrative events but also to the speaker's tentative explanation of the special powers of men in old times. However, despite the supposition on the nature of the whistle also being hearsay, it is not part of the narrative itself, or at least it is not on the same epistemic level (otherwise it would not be introduced by the inferential ma'ak). The co-occurrence of ma'ak and bin in the same clause confirms that their values are distinct though not incompatible, and are clearly connected to the same domain of reference to cultural knowledge. The use of wale' in final position of the ma'ak clause reinforces the hypothetical character of the inference.

Whereas the use of the reportative bin is rampant in traditional narratives, ma'ak is used much less systematically and does not constitute an index of this genre. The following example clearly shows how ma'ak introduces the speaker's inferences and epistemic judgements on events repeated in canonical stories. This example is also very revealing of the specific values that ma'ak does or does not convey in terms of evidential access and epistemic symmetry.

After a conversation on various subjects, mostly surrounding the guardian spirits of different forest places, I had asked Don Torib, a man in his 70s, if the cenotes (the natural wells formed in sinkholes characteristic of the Yucatan peninsula) also have guardians. He answers affirmatively, but frames his assertion with two hearsay markers, the reportative bin and the reduced form ya'ala (> kuya'alal 
"it is said"), and in so doing, he explicitly roots his assertion in shared traditional knowledge. Don Torib then tells a well-known story about a "waterer" who got caught by a snake in a cenote, and whose rifle exploded so powerfully, it made the cenote collapse. With this story, Don Torib is suggesting that the "guardians of the water" or "of the cenote", about whom I had just asked, are in fact the $a j$ jóo'ya'o'ob "waterer" guardian-spirits. Mayas commonly believe that these beings inhabit the lower layer of the sky and come down to earth to fill their gourds from the cenotes; with this water, the "waterers" create rain.

Notice first that the speaker introduces the aj jóo'ya" "waterer" character with ma'ak, a quite unusual incipit for a Maya folk story (line 3). This reveals that the speaker is still preparing his arguments at that point, using ma'ak to make explicit the inferential nature of the equivalence he is establishing between "the master of the water" (uyuumil ja') and the "waterer" from the sky (aj jóo'ya'). The speaker then continues the story, constantly punctuating his words with the reportative bin and other hearsay markers, as is usually the case for traditional narratives (lines 4-36). It is only after the end of the story that ma'ak shows up again. Don Torib uses it twice, this time to equate the explosion produced by the rifle (on earth, at the cenote) with celestial thunder and lightning. This is done with a two-step/two-ma'ak inference: firstly, by suggesting that the sound of the rifle was just like the sound of thunder, and secondly, by suggesting that the small rifle found near the cenote must have been the same weapon that thunders in the sky. In both ma'ak sentences, Don Torib explicitly appeals to my personal knowledge: to my experiential knowledge in the first sentence (lines 37-40): "like when you hear the thunder of the lightning"; and to my knowledge of things "that are said" in the second (lines 41-46): "don't you hear its shake, its explosion; and you hear it is said the guardian spirits are shooting, it is said. that's it, that thing thunders". ${ }^{13}$ Therefore, in this example, the speaker appeals to both traditional cultural knowledge and the addressee's experience. Ma'ak is used to draw on shared collective knowledge of the matters in which the inference is rooted, while explicit references to the addressee's experience are made to include this knowledge as part of the shared knowledge. As for the supposition (inference) itself, it is not symmetric, but is what Don Torib wants me to understand.

(22) 1. Ka' bin úuch bin unp'ée beesak bin úuch bine' They say it happened once, they say, a long time ago, they say (+ 1 they say)

13 Notice also that in these sentences, the reportative bin is not used in the same way as it was in the previous part, and this creates a clear contrast with the storytelling section.
2. kya'ik bin e máak bino' the guy says, they say,

3. pero mak (.) aj jo'yab e le éem-Ø bey ch'u_chup pero INF.C (.) AG to.water DET DET go.down-B3 MOD fill_fill in u-chuuj-o,

A3-calabash- $\mathrm{TD}_{2}$

but maybe it was the waterer who went down to fill his gourd

4. ti' yáana tun bine 'áaktun beya'

below the cave, they say, like this,

5. ti' yaan u yook yáan e 'áaktuno' beey tuchupk uchan chuuj beya' his feet were under the cave's stone while he was filling his little gourd like this...

6. kya'ikbin ti'e' he says they say

7. túuchupk uchuuj bine' he was filling his gourd, they say

8. e kutíip'l ula' juntúu máak beey kóomo ja' de uk'bile' when another man appears, since it was drinking water...

9. ka' taal uch'a ja' bini' and he came to fetch water they say,

10. kya'ala bin ti', kya'ik bin e máako' it is said to him, they say, the guy says, they say

11. ichil uchupk uchuuj e aj jóo'ya'óo' máa ka' chu'uki' As the waterer was filling in his gourd, suddenly he got caught

12. ka'j k'a'ax men junp'e (no)xi kaan and he got tied up by a big snake

13. t ujool le ja' beyo', kya'ik bine'= at the entrance of the water source like this, he says they say (...) (...) (here a section of the narrative is omitted for reasons of space)

36. Tuntronáart e' ba'alo' ka j k'aschaj e (.) ts'ono'ot bino' The thing thundered and the cenote got ruined.

37. Ma'klee ma'k (.) je'ex je'ex u-tronar raayo k-aw-uy-ik INF.C DET INF.C as as A3-thunder lightening ICP-A2-hear-IPF.TR It must have been like when you hear the thunder of the lightning 
38. [bey uwa'ak'a] uwíinkili máak bey úuchk utronark le ts'ono'oto'! just like a body explodes, that's how the cenote thundered!

39. kaj ts'o'okej nojochajij and after that, it got bigger

40. bey bin

that's how it is they say

(... .... 30 s. not reproduced)

41. Ma'ak le ba'a taa-s-a'ab-e'

INF.C DET thing come-CAUS-PAS.PF-TD

It must have been the thing that he brought (lit. was brought)

42. lete' le k-u-tronar-o' te' ka'an-l-o',

PR3 DET ICP-A3-thuunder-TD ${ }_{2}$ LOC sky-NOM-TD that thundered in the sky,

43. máa' [k]awuyik u ukîllba uwa'ak'a, don't you hear its shake, its explosion;

44. kawuyikya'alalo' tunts'oonóo' le yúuntsilo'obo' kya'alale' and you hear it is said the guardian spirits are shooting, it is said

45. aja lete' je'elo' kutronartik le' ba'a je'lo'. that's what it is, the thing that thunders things.

46. Bey bin.

That's how it is they say.

[tor-D3G4P2-2007]

The examples above are typical of the majority of the instances of ma'ak found in our corpus, in that they involve non-subjective indirect access to the evidence on which the inference is based, and concern different kinds of traditional collective knowledge. Since they concern traditional collective knowledge, they also tend to imply symmetry of knowledge. Indeed in these cases, we have seen that most instances also imply the speaker's supposition or expectation that both the evidence and the inference are shared by others, usually - but not always - the other speech participants. This is seen in example (19) because the speaker is convinced that his addressee knows more than he does about what he is supposing, in example (20) because the inference reflects a shared conjecture, and in example (21) because the inference is grammatically marked as hearsay. However, notice that in (21) the inference is marked as shared with others (hearsay), but is not expected to be shared by the addressee (myself). The last example (22) shows a similar but more complex situation in which ma'ak is used because the speaker thinks the knowledge behind the inference is shared (either as common experience or as common traditional lore) but the epistemic judgement is not (although the speaker's aim is to change this).

\subsection{Ma'ak in the context of situations experienced}

The next examples are especially instructive because they present cases in which ma'ak modalizes statements related to autobiographical events. In this context, the subjective mín rather than ma'ak would be expected in terms of knowledge access and asymmetry. But we will see that in fact, despite being rooted in a personal experience, the inference introduced by ma'ak always concerns an aspect of the situation to which the speaker has only non-subjective or mediated access, following the general pattern of ma'ak uses.

This is clear in example (23). The situation mentioned is a very concrete event that the speaker, an elderly woman, experienced and is remembering: while hunting, she got trapped in a cave after a stone fell and blocked the entrance. The speaker then speculates about why the cave closed, and ma'ak introduces the hypothetical cause. Notice however, that the cause is not related to anything the speaker has directly seen or experienced. It is instead related to a supernatural power, the guardian-spirit of the cave, knowledge of which is, as we saw in (20), indirect, based on comments and stories of all kinds (see also Vapnarsky 2013b). This reference to common and mediated knowledge can explain the use of ma'ak.

(23) 1. Pos leti', mak u-yuum-il le 'áaktun CONJ PR3 INF.I A3-master-NOM DET cave well it's him, it must be the guardian of the cave

2. leti' leen-chïn-t-ej le ba'a t-inw-óok'ol-o', leti’! PR3 flash-throw.at-TRZER-B3.SBJ DET thing PREP-A1-on-REL-TD 2 PR3 he's the one who threw the thing on me, it's him!

3. Yaan uyuumil (...) (...) la'tene' tunmeetiko' teen beyo'. It [the cave] has its guardians, that's why they did that to me.

[xisa-vva0154-1996]

The following example involves another type of mediation. It is taken from the account of a boy abducted by guardian-spirits and taken to live with them for some time. In quoted speech, the extract presents the dialogue between the parents and the son, now back home. At first sight, ma'ak seems clearly unexpected here because it introduces a statement relating to an action of which the boy was the 
direct patient, and which is reported as verbatim quotation. However, notice that this action took place when the boy was living with the guardian-spirits, in a some-what different world, and in an abnormal state of consciousness. Ma'ak appears to index the indirect perception of this extraordinary experience. Here it might also be used as a way of creating a sense of distance while relating events that, according to cultural values, should be left unmentioned, or be only very vaguely referenced.

(24) 1. - Ay pero núux, kuya'alaj bin ti', yaan takx nóok'ol tech!

Oh but son, it was said to him they say, you even have worms!

2. - Xúib yaan wale’, (...) pos teene’, teene’ tin-máan, Man, I have maybe (...) well me, me, I was going,

3. chen ween-(e)k-en, ma'ak tun-ts'a'ab-a ten xnóok'ol just sleep-SBJ-1B INF.C PROG.A3-give-PAS-IPF PR1 worm wal-e, kij bin... POSS - $\mathrm{TD}_{4}$ QUOT RS and when I went to sleep, maybe they put worms on me (lit. I was put worms) maybe, he said they say...

[mak-vva0087-1996]

The last example in this section is probably the most atypical of our corpus. It is nevertheless perfectly explainable from what we saw before. The sentence was spoken by a young mother while she was bathing her little girl in an elevated washing tub. The girl laughs with joy. The mother then tells of another child she oncesaw, a boy who cried and resisted while being bathed in the same way. Using ma'ak, she then hypothesizes that the boy might have been suffering because he was not used to that way of bathing. The speech event takes place in the kitchen of her mother-in-law (where the girl's mother lives) with various family members around. None of them knows the boy she is talking about.

(25) Mak ma'súujk uy-ich-kúun-s-a'a(l) bey-o'

INF.C NEG HAB A3-bathe-FACT-CAUS-PAS.IPF MOD-TD

Maybe he wasn't used to being bathed like that?!

[fieldnote-2012]

The speaker is reporting a situation she observed, and is drawing an inference about this situation. There is clearly asymmetric knowledge, since the inference is addressed to speech participants who were not present when the reported event occurred. Despite the fact that this asymmetry and the speaker's perceptual access to the evidence (the boy crying) would make miin the expected inferential, ma'ak is used instead. We can identify a number of relations - of the speaker to the reported facts, as well as to the speech participants' assumed knowledge - that lead the speaker to use $m a\left({ }^{\prime} a\right) k$ : (i) perceptual and corporal mediation (the mother observed the situation but she was not bathing the child herself; the child was bathed by a third person who is absent from the speech situation): ${ }^{14}$ (ii) inference addressed to a third party (the mother is addressing not the person who was bathing the boy, nor the boy himself, but rather people who did not observe the situation; this context can be contrasted with the uses of miin in questions, seen in section 2.4.1); (iii) the inference has to be confirmed by drawing on second-hand cultural knowledge (given that the speech event participants have no access to aspects or participants of the reported bathing situation). ${ }^{15}$ All of these elements converge to exclude the use of miin in this experienced situation and, by contrast, to justify the use ma'ak.

\subsection{Ma'ak: The lack of coding of knowledge symmetry}

We have seen that all of the instances of ma'ak found in our corpus reflect various types of knowledge-access indirectness, but mainly relating to references to shared collective knowledge. The recurrent use of ma'ak to draw inferences from this type of knowledge may lead to the analysis that ma'ak is a marker of symmetric knowledge. However, some of the previous examples did not fit this analysis ((21), (22), (25)). Other examples, some of them from elicitation sessions, confirm that symmetry of knowledge is not a necessity. For instance, ma'ak was chosen in an imaginary context in which a speaker, seeing seeds he did not know about as a child (tumen teene' ma' inwili' "because I didn't see them (the seeds)") assumes they did not exist back then. He comments on this to a co-worker, asking for confirmation:

(26) Ma'ak mina'an áa úuchij?

INF.C EXIST.NEG INTER in.the.old.times

Doesn't it seem that there weren't any before?

[elicitation-epist-2012]

The interviewee improvised an answer for the addressee, who contradicts the inference, replying that the seeds must have existed because his grandfather told him so. The fact that ma'ak was used in a polar question, and that the answer is incongruous with the proposition introduced by ma'ak, reveals that symmetry of knowledge was not expected by the speaker.

14 See also Kwoon (2012: 963) on the use of an indirect inferential marker in Korean with third-person subject experiential predicates.

15 In a way, this is similar to example (19) with the speaker asking for help to confirm a hypothesis based on cultural knowledge. 


\subsection{Prevalence of collective-general knowledge over visual access}

Interestingly, the elicited data also reveals a preference for ma'ak when the inference concerns matters of the past and of collective history, even if the evidence also comes from personal memory or perceptual access. This was already present in the earlier example where the speaker, imagining thescene associated with the ma'ak sentence, said that he was drawing his inference from old memories. This is even more striking in the contrast between the next two examples. In (27), the imagined situation involves a person discovering traces of an old wall in the forest, and inferring that there once must have been a village at that location. She expressed this with ma'ak.

(27) 1. Ma'ak yan-Ø máak kaaj-l-a’an-Ø way úuch-ej INF.C EXIST-B3 person village-posit-PART-B3 here long.ago- $\mathrm{TD}_{4}$ It seems there were people living here before.

2. pos tumen umeyajo' way p'aatla', wa kex nukuch máakóo' meetej. Well because, their work has stayed here, it could have been done by old generations.

[elicitation-epist-2012]

In (28), the speaker was asked to imagine someone discovering that a stool had changed place in her house while she and the other inhabitants were absent, and inferring from this that someone must have entered the house. In this case, the speaker clearly preferred to express the inference with miin: ${ }^{16}$

(28) 1. mín yaan- $\varnothing$ máak óok- $\varnothing$ in-na(j)-i,

INF.S EXIST-B3 person enter-B3 PREP A1-house-NOM

Apparently someone entered my house,

2. ba'an.ten le ba'al-a' bey yaan-ik-a'? (..) miin yaan- $\emptyset$ máak WHY DET thing-TD 1 MOD EXIST-MAF-TD ${ }_{1}$ INF.S EXIST-B3 person óok way-e?

enter-B3 here- $\mathrm{TD}_{3}$

why is this thing like this? (.) Apparently someone entered here.

3. Beey, inwa'ake' yan máak óok waye'. Aaja ooko máak waye'! kech xan That's it, I'd say someone entered here. Aha, someone has entered here! You (should) say also.

[elicitation-epist-2012]
Both situations imply that the inference is drawn from visible evidence. However, in the first case, the epistemic judgement is also informed by common local historical knowledge about the existence of abandoned dwellings in the forest, and this led to the use of ma'ak. By contrast, the second case corresponds to an individual fact linked to present-day life and the immediacy and singularity of a situation that has just occurred and that no one knows about, which triggered the use of miin.

Similarly to the ancient dwelling example, but taken from a natural context, our final example confirms the prevalent relation of ma'ak to matters of traditional knowledge. When I asked a friend if Maya had been their language since old times, my addressee, a woman in her forties, exclaimed:

\section{(29) - Ma'ak bey-o! \\ INF.C MOD-TD \\ Probably yes, it has!}

She immediately supported her assertion by mentioning that her grandfather used to speak Maya. She had known her grandfather well, and clearly remembered interacting with him in Maya until his death when she was about 20. The evidence she invokes is thus based on personal memory access (which is more of the field of miin). However, as also shown by the above example (26), and as supported by other facts, here the reference to the grandfather mainly serves as a typified source of collective knowledge, which triggers the use of ma'ak.

Examples (27) and (29) show interesting cases in which the evidence comes from both subjective and collective-general knowledge. Remarkably, the fact that the latter is favoured in the marking choice does not follow the common salience hierarchy generally observed for evidential (visual $>$ non-visual $>$ inferred) (Aikhenvald: 2004) or for deictic markers in Yucatec (asymmetric/perceptual > symmetric/ perceptually more distant) (Hanks 1990, 2005) (where > means that the value to the left of the sign outweighs the one on the right, and the marker encoding the "heavier" value is given preference when both compete in a given speech context).

\subsection{Summary of ma'ak and its contrast with miin}

The particle ma'ak signals that the statement under consideration is a partial-support inference based on non-subjective knowledge. This characterization makes it the exact complement of miin. However, I have shown that the evidential anchoring of ma'ak does not apply to any kind of mediated non-subjective access, and that ma'ak is mostly connected to collective-general knowledge. In particular, I have not found cases of ma'ak being used for knowledge that is accessible to 
the other speech participants, especially the addressee, but is inaccessible to the speaker. Since ma'ak appeals to collective-general knowledge, it generally presupposes that the knowledge is shared with the addressee, although this is not always the case. Instances of a speaker using ma'ak based on a presumption of knowledge asymmetry with the speech participants can occur. The speaker might conceive the knowledge as being shared not with the speech participants, but rather with others not present in the speech event. Thus in the strict sense of the definition in the introduction, symmetry of knowledge and intersubjectivity is not codified by this marker.

The fact that ma'ak and miin are not used in intradiscursive, dialogic strategies of agreement and disagreement confirms that they do not primarily encode intersubjectivity (even though ma'ak often anticipates alignment from the other speech participants, because the inference is drawn from collective knowledge, and often resonates with common presumptions or explanations). The same is true concerning the fact that in dialogic exchanges, I did not observe changes from miin to ma'ak that indexed a shift from asymmetric to symmetric knowledge. This dimension is instead expressed by other markers in Yucatec, particularly the pervasively used terminal deictics $a^{\prime}$ (asymmetric) /o' (a/symmetric) which do evolve intradiscursively (Hanks 1990). Nevertheless, it is worth noting that in my corpus, the instances of ma'ak that appear in sentences with terminal deictics all involve the clitic $o^{\prime}$. This is not surprising given that $o^{\prime}$ indexes shared access to the referent, typically associated with collective-general knowledge.

In contrast, mín occurs in utterances with $a^{\prime}$ or $o^{\prime}$, and this correlates with its broader usages, and with the fact that it applies to more varied and indexically complex speech events.

Other correlations would appear to be relevant for understanding the contrast between ma'ak and mín. The particle ma'ak is used with third-person predicates, whereas mín is found with a variety of persons (since the subjective stance it encodes may apply to statements about other people or things, even though first-person predicates are most commonly used because of the subjective access value). The particle ma'ak tends to be used in or next to predicates with the indefinite reportative (bin), whereas míin appears more frequently in quoted speech marked with the quotative ( $k$-ABS) (and this is required in traditional narratives for the measurement-estimation use). Finally, ma'ak does not co-occur with subjective modal attenuators, contrary to miin, which is very commonly found with them. Instead, ma'ak occurs with expressions such as keensa, which signals shared lack of knowledge (Vapnarsky 2012). All of this confirms the link of ma'ak with collective-general knowledge and traditional lore. Table 16.2 below presents the main properties of miin and ma'ak.
Table 16.2: Synthesis of miin and ma'ak properties miin

Access to information

Epistemic judgement

Knowledge symmetry (with respect to speech event)

Typical uses
Subjective ++

Personal

Asymmetric

estimation of measurements; talk about old times, propheconnected with the perceptual matters to which speakers only field of the speaker or direct have mediated access (e.g. the

Combination with person Combination with reportative markers

Combination with

subjective modal attenuators cognitive knowledge

any

quotative

very common non-visible supernatural world) 3rd person indefinite reportative none inference based on premises sied future times, folktales and ma'ak

Non-subjective $=$ Collective-General knowledge Shared

(Symmetric +$)$

\section{Conclusion}

As a general characterization, the particles miin and ma'ak can be defined as partial support inferential markers that contrast on the (inter)subjectivity parameter. However, we have seen that, as commonly understood, this characterization is insufficient for understanding the specific uses and speaker choices connected with this form. Firstly, one needs to determine whether the subjectivity applies to access or to epistemic judgement. Secondly, the pole contrasting with "subjective" needs to be specified. Besides "intersubjective", which I restrict to knowledge as constructed in the speech event, I have proposed to introduce "collective-general" knowledge as a third pole of the (inter)subjective dimension. Thirdly, although (inter)subjectivity often correlates with symmetric/asymmetric knowledge distribution among speech participants, the particles analysed here confirm the need to keep both dimensions very separate. As we have seen with the contrast between Yucatec Maya and Yurakaré, languages with markers conveying apparently very similar values may differ in terms of which dimension is encoded and which is inferred. 
Lastly, the analysis shows that even though mín and ma'ak form a paradigmatic contrast in a two-member syntactic category of inferentials, their use does not cover all possible semantic and pragmatic possibilities relating to inference reasoning (for example inference based on something the speaker has previously heard said about the addressee). This is the case particularly because ma'ak is connected with collective-general knowledge and rarely used for other types of mediated access to knowledge. It is also linked to the scattered distribution of evidentiality in the Yucatec Maya grammatical and lexical system, which is expressed by different sub-groups of particles with limited contrasts. Last but not least, it probably also results from constraints dependent on local linguistic ideologies regarding what can be said and what should remain implicit, as well as on more universal communicative principles of knowledge sharing. To better understand these crucial issues, further investigation will be needed in Yucatec Maya, as well as in many other languages.

Abbreviations: 1 - first person; 2 - second person; 3 - third person; A - SET A (ergative); ADM - admonestative; ADV - adverb; AG - agent; B - SET B (absolutive); CAUS - causative; CONC - concessive; CONJ - conjunction; CP completive; DEM - demonstrative; DET - determinant; DIS - disjunctive; EMPH emphatic; EXIST - existential; FACT - factitive; FEM - feminine; HAB - habitual; ICP - incompletive; IPF - imperfective; INF - inferential; INF.C - collectivegeneral knowledge inferential; INF.S - subjective inferential; INTER - interrogative; INTR - intransitive; IPF - imperfective; LOC - locative; MOD - modal deictic base; like; MAF - manner adverb focus; NC - numeral classifier; NEG - negation; NOM - nominal suffix; OBLIG - obligative; proyective; OST - ostensive; PART - participial; PAS - passive; PF - perfective; PL - plural; PN - proper noun; POSS - possibility; epistemic deictic; PR - independent pronoun; PREP - preposition; PROG - progressive; QUOT

- quotative; REP - repetitive; RS - reported speech; RETROS - retrospective; $\mathrm{SBJ}$ - subjunctive; $\mathrm{TD}_{1}$ - terminal deictic (immediacy, asymmetry); $\mathrm{TD}_{2}$ - terminal deictic (less immediate, symmetric) $\mathrm{TD}_{3}$ - terminal deictic (neutral); $\mathrm{TD}_{4}$ - terminal deictic (topic); TP - temporal; TR - transitive; -VL - suffix attached to nominal and imperfective stems realized as $-V$ (vowel harmony).

\section{References}

Aikhenvald, Alexandra. 2004. Evidentiality. Oxford/New York: Oxford University Press.

Anderbois, Scott. 2013. Míin en maya yucateco: evidencial o modal? Paper presented at CILLA VI, Austin, Texas, October 2013.

Anderbois, Scott. 2016. Illocutionary mirativity: the case of Yucatec Maya bakáan. Paper presented at SULA 9.

Anderbois, Scott. Submitted. Conjecturals seem like evidentials, but they might not be.

Barrera-Vásquez, Alfredo (ed.). 1981. Diccionario Cordemex Maya-Español, Español-Maya. México: Editorial Porrúa.

Beltrán de Santa Rosa María, Pedro. 1859 [1746]. Arte del Idioma Maya reducido a sucintas reglas y Semilexicón yucateco. Mérida : Imprenta de J.D. Espinosa.

Benveniste, Emile. 1958. De la subjectivité dans le langage. Journal de Psychologie. Paris: PUF.

Bergqvist, Henrik. 2015. Epistemic marking and multiple perspective. An introduction. STUF. Language Typology and Universals. Special Issue. Epistemic marking in typological perspective 68 (2). 123-122.

Boye, Kasper. 2012. Epistemic Meaning. A cross-linguistic and functional-cognitive study. Berlin/Boston: De Gruyer.

Bricker, Victoria, Eleuterio Po'ot Yah \& Ofelia Dzul de Po'ot. 1998. A Dictionary of The Maya Language as Spoken in Hocaba, Yucatán. Salt Lake City: University of Utah Press.

Cornillie, Bert. 2009. Evidentiality and epistemic modality. On the close relationship between two different categories. Functions of Language 16 (1). 44-62.

De Haan, Ferdinand. 1999. Evidentiality and epistemic modality: setting boundaries. Southwest Journal of Linguistics 18. 83-101.

De Haan, Ferdinand. 2001. The place of inferential within the evidential system. International Journal of American Linguistics 67 (2). 193-210.

Evans, Nicholas. 2005. View with a view: Towards a typology of multiple perspective. Berkeley Linguistics Society, 31 (5). 93-120.

Faller, Martina. 2002. Semantics and pragmatics of evidentials in Cuzco Quechua. Stanford: Ph.D. thesis.

Gipper, Sonja. 2015. (Inter)subjectivity in interaction: Investigating (inter)subjective meanings in Yurakaré conversational data. STUF. Language Typology and Universals. Special Issue. Epistemic marking in typological perspective, 68 (2). 211-232.

Guentchéva, Zlatka \& Jon Landaburu (eds.). 2007. L'énonciation médiatisée II. Le traitement épistémologique de l'information : illustrations amérindiennes et caucasiennes. Louvain: Éditions Peeters.

Hanks, William F. 1984. The Evidential Core of Deixis in Yucatec Maya. In Proceedings of the Chicago Linguistic Society, 154-172.

Hanks, William F. 1990. Referential practice. Language and lived space among the Maya. Chicago/London: The University of Chicago Press.

Hanks, William F. 2005. Explorations in the Deictic Field. Current Anthropology, 46 (2). 191-220. Hanks, William F. 2007. The evidential core of deixis in Yucatec Maya. In Guentchéva,

Zlatka \& Jon Landaburu: L'énonciation médiatisée II. Le traitement épistémologique de l'information : illustrations amérindiennes et caucasiennes, 311-331. Louvain: Éditions Peeters.

Hanks, William F. 2012. Evidentiality in social interaction. Pragmatics and Society, 3 (2). 169-180. 
Heritage, John. 2012. The Epistemic Engine: Sequence Organization and Territories of

Knowledge. Research on Language and Social Interaction 45(1). 30-52.

Kockelman, Paul. 2004. Stance and subjectivity. Journal of Linguistic Anthropology 14. 127-150. Kwoon, Iksoo. 2012. Please confirm what I inferred: On the Korean

inferential-evidential marker

-napo-. Journal of Pragmatics 44. 958-969.

Langacker, Ronald. 1990. Subjectification. Cognitive Linguistics 1. 5-38.

Langacker, Ronald. 2002. Deixis and subjectivity. In Frank Brisard (ed.), Grounding: The

Epistemic Footing of Deixis and Reference. 1-28. Berlin/New York: Mouton de Gruyter.

Lucy, John. 1993. Metapragmatic presentationals: reporting speech with quotatives in Yucatec

Maya. In John Lucy (ed.), Reflexive language: reported Speech and Metapragmatics,

91-126. Cambridge: Cambridge University Press.

Lyons, John. 1997. Semantics vol. 2. Cambridge: Cambridge University Press.

Narrog, Heiko. 2012. Modality, Subjectivity, and Semantic Change. Oxford/New York: Oxford

University Press.

Nuyts, Jan. 2001, Subjectivity as an evidential dimension in epistemic modal expressions. Journal of Pragmatics 33. 383-400.

Pérez, Juan Pio. 1866-77. Diccionario de la Lengua Maya. Mérida: Imprenta Literaria de Juan Molina Solis.

Portner, Paul. 2009. Modality. Oxford: Oxford University Press.

Stievers, Tanya, Lorenza Mondada \& Jakob Steensig. 2011. The Morality of Knowledge in Conversation. Series Studies in Interactional Sociolinguistics. Cambridge: Cambridge University Press.

Tournadre, Nicolas \& Randy J. LaPolla. 2014. Towards a new approach to evidentiality: issues and directions for research. Linguistics of the Tibeto-Burman Area 37(2). 240-263. Amsterdam: John Benjamins Publishing Company.

Traugott, Elizabeth C. 1995. The Role of the Development of Discourse Markers in a Theory of Grammaticalization. Paper presented at ICHL XII, Manchester 1995; Version of 11/97. http://web.stanford.edu/ traugott/papers/discourse.pdf (accessed 7 June 2017).

Traugott, Elizabeth C. 2003. From subjectification to intersubjectification. In Raymond Hickey (ed.), Motives for Language Change, 124-139. Cambridge: Cambridge University Press.

Traugott, Elizabeth C. \& Richard Dasher. 2002. Regularity in Semantic Change. Cambridge: Cambridge University Press.

Verhagen, Arie. 2005. Construction of Intersubjectivity: Discourse, Syntax, Cognition. Oxford: Oxford University Press.

Vapnarsky, Valentina. 1999. Conceptions et expressions de la temporalité chez les Mayas Yucatèques. PhD Université de Paris X, Nanterre. vol. 2.

Vapnarsky, Valentina. 2012. The grammar of uncertainty in Yucatec Maya. Paper presented at Primer Coloquio Internacional de Estudios de Maya Yucateco, El Colegio de México, D-F, October 2012.

Vapnarsky, Valentina. 2013a. Mandatos y solicitudes: el arte cotidiano del pedir en maya yucateco. In Alain Breton \& Philippe Nondédéo (eds.), Maya Daily Lives, 169-183. Mark Schwaben, Germany: Verlag Anton Saurwein.

Vapnarsky, Valentina. 2013b. Le passif peut-il éclairer les esprits ? Agentivités, interactions et esprits-maîtres chez les Mayas. Ateliers d'Anthropologie. LESC, Nanterre. http://ateliers. revues.org/9449

Vapnarsky, Valentina. 2017. The indexical field of uncertainty. In Valentina Vapnarsky, Senses of time: Exploring temporality in Mayan discourses, experiences and remembrances, chap. 7 , p. 273-291. Manuscript presented for the Habilitation à Diriger des Recherches. Paris: EHESS. 